\title{
Ergenlerde Sosyal Ortamlarda Gelişmeleri Kaçırma Korkusu (Fomo) Yordayıcılarının İncelenmesi
}

\author{
DOI: $10.26466 /$ opus.628081
}

*

\author{
Aslı Kartol* ${ }^{*}$ Adem Peker** \\ * Dr., Milli Eğitim Bakanlığı, Yakutiye/ Erzurum / Türkiye \\ E-Posta: aslikartol@gmail.com \\ ORCID: 0000-0001-8127-0560 \\ ** Doç., Dr. Atatürk Üniversitesi, Kazım Karabekir Eğitim Fakültesi, Yakutiye / Erzurum/ Türkiye \\ E-Posta: adem.peker@atauni.edu.tr \\ ORCID: $\underline{0000-0002-3594-9166}$
}

\section{Öz}

$\mathrm{Bu}$ araştırmanın amacı ergenlerde sosyal ortamlarda gelişmeleri kaçırma korkusunun yordayıcılarını belirlemektir. Araştırmanın çalışma grubunu 2018-2019 güz döneminde Erzurum ili merkezinde bulunan çeşitli liselerde öğrenim gören yaşları 14 ila 18 arasında değişen 517 öğrenci oluşturmaktadır. Öğrencilerin yaş ortalaması 15,93'tür. Araştırmada "Mutluluk Ölçeğì", "Sosyal Ortamlarda Gelişmeleri Kaçırma Korkusu Ölçeği" ile "Çocuklar İçin Depresyon ve Anksiyete Ölçeği" kullanılmıştır. Araştırmada yapılan istatistiksel analizler sonucunda sosyal ortamlarda gelişmeleri kaçırma korkusu ile depresyon ve anksiyete düzeyi arasında pozitif yönde orta düzeyde anlamlı bir ilişkinin olduğ u bulunmuştur. Yapılan çoklu doğrusal regresyon analizi sonucunda anksiyetenin sosyal ortamlarda gelişmeleri kaçırma korkusu davranışının \% 22'sini açıkladığı; ancak depresyonun sosyal ortamlarda gelişmeleri kaçırma korkusu davranışını yordamadığı görülmüştür. Bir diğer bulgu sosyal ortamlarda gelişmeleri kaçırma korkusu davranışı ile mutluluk arasında anlamlı bir iliş̧inin olmadığıdır. Ayrıca cinsiyet değişkeni açısından da sosyal ortamlarda gelişmeleri kaçırma korkusu davranışının kız öğrencilerde daha yüksek olduğu ortaya çımıştır. Sonuç olarak anksiyetenin sosyal ortamlarda gelişmeleri kaçırma korkusunu pozitif olarak yordadığı söylenebilir. Araştırma sonuçları doğrultusunda öğrencilerin anksiyete düzeyini azaltacak çalışmalara yer verilebilir.

Anahtar Kelimeler: Fomo, Sosyal ortam, Depresyon, Anksiyete 


\title{
The Investigation of Predictors of Fear of Missing Out (Fomo) in Adolescents
}

\begin{abstract}
The aim of this study was to determine the predictors of fear of missing out in adolescents. The study group of the study consists of 517 students aged between 14 and 18 studying at various high schools in Erzurum city center in the fall term of 2018-2019. The average age of the students is 15.93. In the study, Happiness Scale, Fear of Evasion in Social Environments Scale and Depression and Anxiety Scale for Children were used in the study. As a result of the statistical analysis, it was found that there was a moderate positive relationship between the fear of missing out and the level of depression and anxiety. As a result of multiple linear regression analysis, anxiety explained $22 \%$ of fear of missing out; however, depression did not predict fear of missing out. Another finding is that there is no significant relationship between fear of missing out and happiness. In addition, it was found that the fear of missing out was higher in female students in terms of gender variable. As a result, it can be said that anxiety positively predicts the fear of missing developments in social settings.In line with the results of the research, studies that reduce the anxiety level of the students can be included.
\end{abstract}

Keywords: Fomo, Social environment, Depression, Anxiety 


\section{Giriş}

Akıllı telefonlar hayatımıza girdiğinden beri internet istenilen her an ve her yerden ulaşılabilir duruma gelmiştir (Giner-Bartolomé ve diğerleri, 2015). Artık insanlar tek tuşla dünyanı öbür ucundaki bir kişiyle görüşme yapabilmekte ve çok hızlı bir şekilde veri alışverişinde bulunabilmektedirler. Mobil iletişim araçları kişilerin aileleri veya arkadaşlarıyla iletişim engellerini aşarak zaman ve mekândan bağımsız bir şekilde metinler, resimler veya sesli mesajlar aracılığıyla iletişimde kalmalarını sağlamaktadır. Bu nedenle mobil iletişim, sosyal bağlantıyı artırmanın yanı sıra her an bağlı olma ve aidiyet ihtiyacını da karşılar niteliktedir (Deci ve Ryan 2012).

Teknoloji ile bağlantılı olarak insanlar için artık dijital dünya vazgeçilmez ve yokluğunda tahammül sınırlarını zorlayan bir hal almıştır. Küresel dünyada yaşanılan birçok sorun ya da korkuya artık telefon şarjının bitmesi, internet paketinin tükenmesi, akıllı telefonunu evde unutma gibi korkular eklenmiştir ve bu durum küresel bir fenomen halini almıştır (Schreckinger, 2014). FOMO (feeling of missing out, fear of missing out) son zamanlarda hızla yayılan bu fenomenlerden biridir. Türkçeye "sosyal ortamlarda gelişmeleri kaçırma korkusu" olarak giren bu kavramı korkudan kavramsal olarak ayrılmasından dolayı, "eksik hissetme" olarak kavramsallaştırmak mümkündür (Przybylski, Murayama, DeHaan ve Gladwell, 2013). Eksik hissetme ile belirli bir anda alınan bilgiler tarafından tetiklenen ve mevcut durumun yönelimini gösteren eksiklik duygusu ima edilmektedir. Çevrimiçi, laboratuvar ve saha çalışmalarına dayanarak, FOMO “bireylerin kendilerinin bulunmadıkları ortamlarda meydana gelen olumlu deneyimlere karşı yaşadıkları şiddetli mahrumiyet duygusu" olarak tanımlanmaktadır (Hayran, Anik ve Gürhan-Canli, 2017).

FOMO kavramına bağlı olarak sosyal medya kullanımının artmasının, kullanıcıların sosyalleşme veya yeni deneyimler ve firsatlardan eksik kalma endişesini artırdığı ortaya konmuştur (Taylor, 2019). Przybylski, Murayama, DeHaan ve Gladwell (2013) konuyu inceleyen ilk psikoloji makalelerinde eksiklik korkusunu "başkalarının ödüllendirici bir deneyim yaşayabileceği korku" şeklinde tanımlamışlardır. Popüler medyada, FOMO'nun sosyal medyanın yayılmasıyla güçlendiği ve bu sayede eksik olan deneyimlerin farkında olmanın hiç olmadığı kadar kolay olduğu belirtilmiştir (Worthman, 2011). 
Anksiyete ve depresyon birbirlerini tetikleyen ve birbirine eşlik eden rahatsızlıklardandır (Avenevoli, Stolar, Li, Dierker ve Ries, 2001). Ak1llı telefonun bağımlılık yaratan kullanımı zihinsel sağlık problemleriyle, özellikle de depresyon ve anksiyete semptomlarıyla ilişkilidir (Elhai, Levine ve Hall, 2019). Depresyon ve anksiyete bozuklukları yetişkinlerde sık görülen rahatsızlıklar olmasına rağmen günümüzde çocukluk ve ergenlikte de deneyimlenebilen psikolojik sorunlar arasındadır (Miller, 2002; Parker ve Roy, 2001). Bu rahatsızlıklar kişinin okul ya da iş hayatını, çevresiyle olan ilişkilerini ve sosyal hayatını olumsuz etkilemektedir $(\mathrm{Hu}-$ berty, 2012). Çocuklar ve ergenlerde sıkça birlikte görülebilmektedirler (Francis, 1993). Hem anksiyete hem de depresif bozukluklardan etkilenen bireyler, yalnızca bir psikiyatrik bozukluğu olan bireylere (depresyon veya anksiyete bozukluğu) kıyasla, genel olarak daha fazla işlevsel bozulma, düşük yaşam kalitesi ve daha olumsuz seyreden tedavi sonuçları göstermişlerdir (Albrecht ve Herrick, 2007). Dolayısıyla depresyon ve anksiyete bozuklukları özellikle kritik olan ergenlik döneminde kişiye bilişsel, duygusal ve sosyal açıdan ciddi olumsuzlar yaratan rahatsızlıklardandır (Weller ve diğerleri, 2002).

Andreassen ve diğerleri (2016) sosyal medyayı aile baskısından uzaklaşma aracı olarak gören ergenler arasında daha yaygın olduğunu belirtmiştir. Bu noktada görsel medya ya da internet kişilere daha popüler ve çekici olabilmek için son çıan akıllı telefon veya en iyi marka ayakkabıya ihtiyacımız olduğunu söylemektedir (Nielsen, 2014). FOMO ile ilgili yap1lan çalışmalara bakıldığında, Schmidt, Muench, Schneider, Breitenbach ve Carolus (2018) yapmış oldukları bir laboratuvar çalışmasında yedi dakikalık bir bekleme süresinde bir odada yalnız başlarına telefonla ya da telefonsuz oturan katılımcilar arasında telefonsuz oturan katılımcların daha fazla kaygı duyduklarını gözlemlemişlerdir. Hayran, Anik ve Gürhan-Canli, (2017) 936 katılımcının katıldığı araştırmalarında katılımcıların \% 81'inin, FOMO'yu en azından ara sıra ya da daha sık yaşadığını bildirmişlerdir. Aynı zamanda FOMO'nun pişmanlık hissi uyandırmadığı da bu çalışmada ortaya çıkan sonuçlardandır. Milyavskaya, Saffran, Hoper ve Koestner (2018) yaptıkları araştırmada FOMO'nun daha sık yaşandığı deneyimler, yorgunluk, stres, fiziksel semptomlar ve azalmış uyku dâhil, hem günlük hem de dönem boyunca olumsuz sonuçlarla ilişkilendirmişlerdir. Araştırma bulguları öğrencilerin FOMO'yu sık sık, özellikle gün 
sonu ya da haftasonu; ders çalışmak gibi gerekli bir işi yaparken yaşadıklarını göstermiştir. Bu sonuçlar FOMO'nun ergenlerin yaşantısında önemli sorunlara yol açtığını göstermektedir.

Araştırmada fomo ile ilgili ele alınan bir diğer kavram mutluluktur. Pozitif psikolojide bu kavram "öznel iyi oluş" olarak karşımıza çıkmaktadır (Tuzgöl Dost, 2016). Diener (2000) ise öznel iyi oluşu bireyin yaşamış olduğu olumlu ve olumsuz deneyimlerinin tümü ile ilgili kişinin öznel değerlendirmesi olarak dile getirmiştir. Dunn, Aknin ve Norton (2008) bireylerin sahip olduklarından ziyade dış koşullarının mutluluk için en belirleyici şey olduğunu belirtmiştir.

Literatürde öznel iyi oluş ile fomo arasındaki ilişkiye doğrudan bakan bir çalışmaya rastlanmamış olsa da, benzer bazı çalışmalar mevcuttur. Kutlu ve ark. (2016) 255 üniversite öğrencisi üzerinde internet bağımlılığ ile mutluluk arasındaki ilişkiye bakmış ve aralarında negatif yönlü anlamlı bir ilişki olduğunu bulgulamışlardır. Benzer bir şekilde Özteke ve ark. (2019) akıllı telefon bağımlılığı, genel aidiyet ve mutluluk arasındaki ilişkiyi incelediği araştırma sonucunda akıllı telefon bağımlılığının mutluluk ile negatif yönde anlamlı bir ilişkisinin olduğunu ortaya koymuşlardir.

Telefonların aşırı ve kontrolsüz bir şekilde kullanımı, bağımlılık haline gelmektedir (Griffiths, 2008). Türkiye İstatistik Kurumu (TÜIK) istatistiklerine bakıldığında bilgisayar kullanım yaşının 8 yaşa, akıllı telefon kullanım yaşının ise 10 yaşa düştüğü bildirilmiştir (TÜİK, 2013). Ayrıca FOMO'nun daha fazla depresyon, anksiyete ve fiziksel semptomlarla ilişkili olduğunu belirten birçok çalışma mevcuttur (Baker, Krieger ve LeRoy 2016; Elhai, Levine, Dvorak ve Hall 2016, Wolniewicz, Rozgonjuk ve Elhai, 2019). FOMO'nun belki de en büyük dezavantajı, insanları şu andaki deneyimlerinden uzaklaştırmasıdır (Milyavskayave diğerleri, 2018). Bu açılardan bakıldığında özellikle ergenlik döneminde yaşanabilecek olan bu bağımlılığın ileride depresyon ve anksiyete bozuklukları ile ilişkisi incelenerek olası önleyici çalışmaların yapılabilmesi açısından literatüre katkı sağlayacağı düşünülmüştür. Bu yüzden bu araştırmanın amacı; ergenlerde sosyal ortamlarda gelişmeleri kaçırma korkusunun yordayıcıları olarak depresyon, anksiyete ve mutluluk arasındaki ilişkiyi incelemektir. Ayrca çalışmada ergenlerin sosyal ortamlarda gelişmeleri kaçırma korkusunun cinsiyete göre farklılaşma durumu da incelenecektir. 


\section{Yöntem}

\section{Araştırma Modeli}

Ergenlerin, sosyal ortamlarda gelişmeleri kaçırma korkusu ile mutluluk, depresyon ve anksiyete düzeyleri arasındaki yordayıcı ilişkilerin incelen-

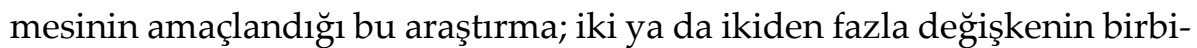
rini etkileyip etkilemediğini ortaya çıkarmaya yarayan ilişkisel araştırma modeli üzerine kurgulanmıştır (Creswell, 2011). Araştırmanın bağımlı değişkenini sosyal ortamlarda gelişmeleri kaçırma korkusu oluştururken, bağımsız değişkenlerini ise cinsiyet, mutluluk, depresyon ve anksiyete oluşturmaktadır.

\section{Çalışma Grubu}

Araştırmanın çalışma grubunu Erzurum merkezinde bulunan Mehmet Akif Ersoy Anadolu Lisesi, Necmettin Erbakan Fen Lisesi ve Nurettin Topçu Sosyal Bilimler Lisesinde 9, 10 ve 11. sınıflar arasında öğrenim gören 517 öğrenci oluşturmaktadır. Öğrencilerin yaşlarının 14 ila 18 arasında değiştiğigözlenmektedir. Öğrencilerin demografik özellikleri Tablo 1'de gösterilmiştir.

Tablo 1. Lise öğrencilerinin demografik özellikleri

\begin{tabular}{llll}
\hline Lise Öğrencilerinin Demografik Özellikleri & $\mathbf{N}$ & $\mathbf{\%}$ \\
\hline Cinsiyet & Kiz & 289 & 55,9 \\
& Erkek & 228 & 44,1 \\
\hline Okul Türü & Anadolu Lisesi & 243 & 47 \\
& Fen Lisesi & 101 & 19,5 \\
& Sosyal Bilimler Lisesi & 173 & 33,5 \\
\hline Yaş & 14,00 & 31 & 6 \\
& 15,00 & 150 & 28 \\
& 16,00 & 177 & 33,8 \\
& 17,00 & 161 & 30,4 \\
& 18,00 & 9 & 1,7 \\
\hline & & 517 & 100 \\
\hline
\end{tabular}

Tablo 1'de öğrencilerin cinsiyetlerine göre dağılımları incelendiğinde \% 55,9'unun kız ( $\mathrm{n}=289)$, \% 44, 1'inin ( $\mathrm{n}=228)$ erkek olduğu görülmektedir. Öğrencilerin öğrenim gördükleri okul türüne göre dağılımları incelendiğinde yaklaşık \% 47'sinin Anadolu Lisesi, \%33'ünün Sosyal Bilimler Lisesi 
ve \%19'unun Fen Lisesinde olduğu gözlenmektedir. Çalışmaya katılan öğrencilerin yaş özellikleri incelendiğinde en çok 16 ve 17 yaşında olduğu belirlenmiştir.

\section{Veri Toplama Araçlan}

Mutluluk Ölçeği: Ölçek, lise öğrencilerinin mutluluk düzeyini ölçmek için Demirci ve Ekşi (2018) tarafından geliştirilmiş, 6 madde ve tek altboyuttan oluşmaktadır. Ölçeğin Cronbach alfa katsayısı .83 olarak bulunmuştur. Bu çalışma kapsamında ölçeğin iç tutarlık güvenirlik katsayısı .84 olarak belirlenmiştir. Mutluluk ölçeğinin lise öğrencileri için geçerliğini belirlemek için doğrulayıc faktör analizi (DFA) yapılmıştır. Uyum indeksleri değerleri $(\mathrm{x} 2 / \mathrm{sd}=2,76 ; \mathrm{NFI}=.99 ; \mathrm{CFI}=.99 ; \mathrm{RFI}=.98 ; \mathrm{AGFI}=.96$, GFI= .99; SRMR $=.024 ; \mathrm{RMSEA}=.058 ; \mathrm{CI}(\mathrm{RMSEA})=.073-.090$ ölçeğin doğrulandığını işaret etmektedir. Ayrıca ölçeğin t değerleri 8.94 ile 23.51 arasında değişmesi uyum değerlerinin anlamlı olduğunu göstermektedir. Bu sonuçlar mutluluk ölçeğinin lise öğrencileri için geçerli olabileceği şeklinde değerlendirilebilir.

Sosyal Ortamlarda Gelişmeleri Kaçırma Korkusu Ölçeği (SOGKKÖ): Ölçek, bireylerin sosyal ağlardaki gelişmeleri kaçırma korkusunu ölçen ve Gökler ve diğerleri (2016) tarafından geliştirilmiş, 10 madde ve tek alt boyuttan oluşmaktadır. Ölçeğin Cronbach alfa katsayısı .81 olarak bulunmuştur. Bu çalışma kapsamında ölçeğin iç tutarlık güvenirlik katsayısı .82 olarak belirlenmiştir. SOGKKÖ’nün lise öğrencileri için geçerliğini belirlemek için doğrulayıc faktör analizi (DFA) yapılmıştır. Uyum indeksleri değerleri (x2/sd= 3,86; NFI = .95; $\mathrm{CFI}=.96 ; \mathrm{RFI}=.93$; $\mathrm{AGFI}=.92, \mathrm{GFI}=.96$; $\mathrm{SRMR}=.060 ; \mathrm{RMSEA}=.074 ; \mathrm{CI}(\mathrm{RMSEA})=.061-.089$ ölçeğin doğrulandı̆̆ını işaret etmektedir. Ayrıca ölçeğin t değerleri 8.11 ile 14.90 arasında değişmesi uyum değerlerinin anlamlı olduğunu göstermektedir. Bu sonuçlar SOGKKÖ'nün lise öğrencileri için geçerli olabileceği şeklinde değerlendirilebilir.

Çocuklar İçin Depresyon ve Anksiyete Ölçeği: Ebesutani ve ark. R-tarafından (2012) geliştirilen bu ölçek; Ay ve diğerleri (2017) tarafından Türkçeye uyarlanmıştır. Ölçek depresyon ve anksiyete boyutlarından oluşmaktadır. 
Ölçeğin depresyon ve anksiyete alt boyutları için Cronbach alfa katsayısı sırasıyla. 87 ve .85 olarak ortaya çıkarılmıştır. Bu çalışma kapsamında depresyon boyutu iç tutarlık güvenirlik katsayısı .83 ve anksiyete boyutu için .81 olarak belirlenmiştir.

\section{Işslem}

Araştırma yapılmadan önce farklı lise türlerinden okullar rastgele olarak belirlenmiş;gerekli uygulama izinleri alınarak öğrencilere öncelikle araştırma amacı anlatılmış ve daha sonra araştırmaya katılmak isteyen gönüllü öğrencilere ölçekler uygulanmıştır. Öğrencilerin veri toplama araçlarını ortalama 15 dakika içinde yanıtlandığı gözlenmiştir.

\section{Verilerin Analizi}

Verilerin analizinde ergenlerin cinsiyete göre sosyal ortamlarda gelişmeleri kaçırma korkusu davranışı arasında anlamlı farklılık olup olmadığı “bağımsız örneklemler için $\mathrm{t}$ testi ile incelenmiştir. Ergenlerin sosyal ortamlarda gelişmeleri kaçırma korkusu davranışı, mutluluk, depresyon ve anksiyete düzeyleri arasındaki ilişkiler ise Pearson korelasyon analizi ile saptanmıştır. Bununla birlikte araştırmada mutluluk, depresyon ve anksiyetenin sosyal ortamlarda gelişmeleri kaçırma korkusu davranışı üzerindeki yordayıc ilişkisi ise çoklu doğrusal regresyon analizi ile test edilmiştir. Analizler için SPSS-22 istatistik programı kullanılmıştır. Verilerin normallik varsayımını karşılayıp karşılanmadığını belirlemek için basıklık ve çarpıklık değerlerine bakılmıştır. Sonuçlar Tablo'2 de gösterilmiştir.

Tablo 2. Araştırmada kullanılan değişkenlere ilişkin betimsel istatistikler ve basıklık ve çarpıklık değerleri

\begin{tabular}{llllllll}
\hline \multirow{2}{*}{ Değişkenler } & $\mathbf{N}$ & $\begin{array}{l}\text { Aritmetik } \\
\text { Ortalama }\end{array}$ & $\begin{array}{l}\text { Standart } \\
\text { Sapma }\end{array}$ & Basıklık & \multicolumn{2}{c}{ Çarpıklık } \\
\cline { 2 - 7 } & İstatistik & İstatistik & İstatistik & İstatistik & $\begin{array}{l}\text { Standart } \\
\text { Hata }\end{array}$ & İstatistik & $\begin{array}{l}\text { Standart } \\
\text { Hata }\end{array}$ \\
\hline SOGKK & 517 & 22,85 & 7,59 &, 45 &, 11 &,- 03 &, 21 \\
Mutluluk & 517 & 20,03 & 5,45 &,- 22 &, 11 &,- 25 &, 21 \\
Depresyon & 517 & 23,02 & 6,38 &, 39 &, 11 &,- 31 &, 21 \\
Anksiyete & 517 & 27,78 & 7,44 &, 52 &, 11 &,- 05 &, 21 \\
\hline
\end{tabular}


Tablo 2 incelendiğinde verilere ilişkin çarpıklık ve basıklık değerlerinin +2 ila -2 arasında olması araştırmaya ilişkin değişkenlerin normallik varsayımını yerine getirdiği şeklinde değerlendirilmektedir (Büyüköztürk, 2017).

Çok değişkenli verilerin normallik ve doğrusallık dağılımı için saçılma diyagramı matrisi'ne bakılmıştır. Bu matriste yer alan değişkenler elips şeklinde dağılım gösterirse çok değişkenli normalliğin ve doğrusallığın sağlandığı söylenebilir.

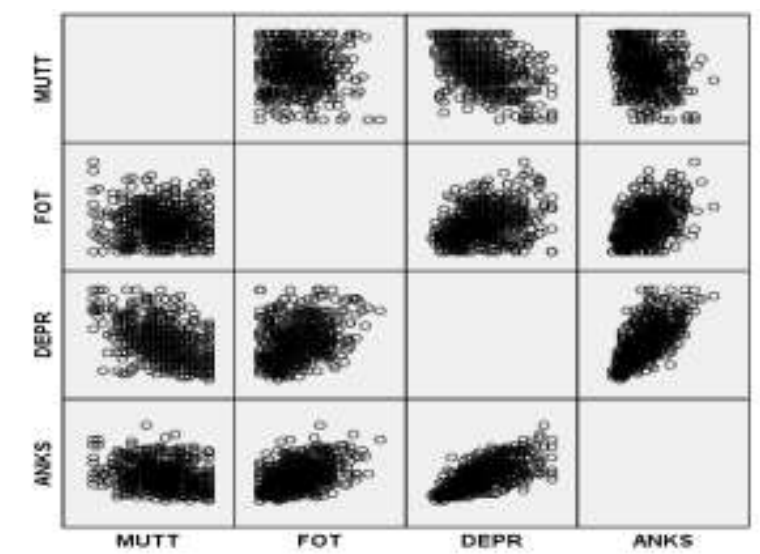

Şekil 1. Değişkenlere ilişkin saçılma diyagramı matrisi

Şekil 1 incelendiğinde araştırma da kullanılan verilerin elips şeklinde olması çok değişkenli veriler için normallik ve doğrusallığın sağlandığının bir göstergesi olarak kabul edilmektedir (Çokluk, Şekercioğlu ve Büyüköztürk, 2014).

\section{Bulgular}

Ergenlerin Sosyal Ortamlarda Gelişmeleri Kaçırma Korkusu Puanlarının Cinsiyete Göre Farklılaşıp Farklılaşmadığı ile İlgili Bulgular

Ergenlerin sosyal ortamlarda gelişmeleri kaçırma korkusu puanlarının cinsiyetlerine göre anlamlı olarak farklılaşıp farklılaşmadığı ile ilgili elde edilen bulgular Tablo 3'de gösterilmiştir. 
Tablo 3. Ergenlerin cinsiyetlerine göre sosyal ortamlarda gelişmeleri kaçırma korkusu puanlarına ilişkin aritmetik ortalamaları, standart sapmaları ve t-testi sonuçlarn

\begin{tabular}{lllllll}
\hline $\begin{array}{l}\text { Bağımlı } \\
\text { Değişken }\end{array}$ & Cinsiyet & $\mathbf{N}$ & $\begin{array}{l}\text { Aritmetik } \\
\text { Ortalama }\end{array}$ & Standart Sapma & $\mathbf{t}$ & $\mathbf{P}$ \\
\hline SOGKK & Kız & 289 & 23,73 & 7,61 & 2,98 & \multirow{2}{*}{$003^{*}$} \\
\hline
\end{tabular}
${ }^{*} \mathrm{p}<.05$

Tablo 3'deki sonuçlar incelendiğinde, ergenlerin cinsiyetleri ile sosyal ortamlarda gelişmeleri kaçırma korkusu arasında anlamlı bir farklılığın olduğu anlaşılmaktadır ( $\mathrm{p}<.05)$. Diğer bir ifade ile kızların erkeklere göre sosyal ortamlarda gelişmeleri kaçırma korkusu anlamlı bir düzeyde daha fazla olduğu görülmektedir.

Ergenlerin Sosyal Ortamlarda Gelişmeleri Kaçırma Korkusu Puanları İle Mutluluk, Depresyon ve Anksiyete Düzeyleri Arasındaki İlişkiler

Ergenlerin sosyal ortamlarda gelişmeleri kaçırma korkusu davranışı puanları ile mutluluk, depresyon ve anksiyete düzeyleri arasındaki ilişki düzeyini ortaya çıkarmak için Pearson korelasyon analizi yapılmıştır. Elde edilen bulgular Tablo 4' de verilmiştir.

Tablo 4. Ergenlerin sosyal ortamlarda gelişmeleri kaçırma korkusu, mutluluk, depresyon ve anksiyete puanları arasındaki ilişkiye ait pearson korelasyon sonuçları

\begin{tabular}{llll}
\hline Değişken & Mutluluk & Depresyon & Anksiyete \\
\hline SOGKK &,- 028 &, $31^{*}$ &, $47^{*}$ \\
$\mathrm{~N}$ & 517 & 517 & 517 \\
\hline
\end{tabular}

${ }^{*} \mathrm{p}<.05$

Tablo 4 incelendiğinde sosyal ortamlarda gelişmeleri kaçırma korkusu davranışı ile depresyon ve anksiyete düzeyi arasında orta düzeyde, pozitif yönde anlamlı ilişkilerin olduğu görülmüştür. Sosyal ortamlarda gelişmeleri kaçırma korkusu davranışı ile mutluluk arasında ise anlamlı bir ilişkinin olmadığı saptanmıştır. Dolayısıyla çoklu regresyon analizine dâhil edilmemiştir. 
Sosyal Ortamlarda Gelişmeleri Kaçırma Korkusu Davranışını Yordayan Değişkenlere İlişkin Bulgular

Araştırmanın bu bölümünde ergenlerin sosyal ortamlarda gelişmeleri kaçırma korkusu davranışlarını yordayıp yormadığına ilişkin çoklu doğrusal regresyon analizi sonuçları yer almaktadır. Çoklu doğrusal regresyon analizi sonuçları Tablo 5'de sunulmuştur.

Tablo 5. Anksiyete düzeyinin sosyal ortamlarda gelişmeleri kaçırma korkusu davranışını yordamasına ilişkin çoklu doğrusal regresyon analizi sonuçları

\begin{tabular}{clllll}
\hline & \multicolumn{2}{l}{$\begin{array}{l}\text { Standartlaştırılmamıs } \\
\text { Katsayılar }\end{array}$} & \multicolumn{2}{l}{$\begin{array}{l}\text { Standartlaştırılmış } \\
\text { Katsayılar }\end{array}$} & \\
\cline { 2 - 4 } Model & B & Standart Hata & Beta & t & p \\
\hline a Sabit & 9,56 & 1,14 &, 47 & 8,37 &, 001 \\
Anksiyete &, 48 &, 04 &, 47 & 12,04 &, 001 \\
\hline
\end{tabular}

Bağımlı Değişken: Sosyal ortamlarda gelişmeleri kaçırma korkusu

$R^{2}=.22, F(1-515)=145,17 ; p<.05$

Tablo 5 incelendiğinde, sosyal ortamlarda gelişmeleri kaçırma korkusu davranışını, anksiyete düzeyinin pozitif bir yönde ve anlamlı bir oranda yordadığı görülmektedir. Çoklu doğrusal regresyon analizi sonuçlarına göre anksiyetenin sosyal ortamlarda gelişmeleri kaçırma korkusu davranışının \% 22'sini açıkladığı görülmektedir.

\section{Sosyal Ortamlarda Gelişmeleri Kaçırma Korkusu Davranışını Yordama- yan Değişkenlerle İlgili Bulgular}

Araştırma da depresyonun sosyal ortamlarda gelişmeleri kaçırma korkusu davranışını yordamadığı bulunmuştur. Bu yordamayan değişkenle ilgili bulgular Tablo 6'da sunulmuştur.

Tablo 6. Sosyal ortamlarda gelişmeleri kaçırma korkusu davranışını yordamayan değişkenlere ilişkin bulgular

\begin{tabular}{lllll}
\hline Yordamayan Değişken & $\mathbf{B}$ & $\mathbf{t}$ & $\mathbf{p}$ & K1smi r \\
\hline Depresyon &, 004 &, 08 &, 94 &, 003
\end{tabular}

${ }^{*} p>.05$ 
Tablo 6 incelendiğinde, depresyonun sosyal ortamlarda gelişmeleri kaçırma korkusu davranışını anlamlı bir düzeyde yordamadığı tespitedilmiştir ( $\mathrm{p}>$.05).

\section{Sonuç, Tartışma ve Öneriler}

Araştırmanın ilk bulgusu incelendiğinde ergenlerin sosyal ortamlarda gelişmeleri kaçırma korkusu ile cinsiyetleri arasında kız öğrencilerin lehine anlamlı bir farklılığın olduğu ortaya çıkmıştır. Araştırmadan elde edilen bir diğer sonuç sosyal ortamlarda gelişmeleri kaçırma korkusu ile depresyon ve anksiyete düzeyi arasında pozitif yönde orta düzeyde anlamlı ilişkilerin olduğudur. Bir diğer değişken olan sosyal ortamlarda gelişmeleri kaçırma korkusu davranışı ile mutluluk arasında ise anlamlı bir ilişkinin olmadığı saptanmıştır. Yapılan çoklu doğrusal regresyon analizi sonucunda ise anksiyetenin sosyal ortamlarda gelişmeleri kaçırma korkusu davranışının \% 22'sini açıkladığı; ancak depresyonun sosyal ortamlarda gelişmeleri kaçırma korkusu davranışını yordamadı̆̆ı görülmüştür.

Araştırmanın ilk bulgusu kızların sosyal ortamlarda gelişmeleri kaçırma korkusu davranışının daha yüksek olduğudur. Yapılan çalışmalar incelendiğinde; Eşer ve Alkaya (2019) kızların sosyal medya bağımlılığ1nın daha fazla olduğunu bulmuşlardır. Bu sonuç birebir FOMO olmasa bile araştırma bulgusuyla örtüşmektedir. Hoşgör, Tütüncü, Hoşgör ve Tandoğan (2017) üniversite öğrencileri üzerinde yaptıkları çalışmada fomonun cinsiyet açısından farklılaşmadığını bulgulamışladır. Yine Gökler ve diğerleri (2016) fomonun cinsiyete göre değişmediğini ortaya koymuşlardır. Kız öğrencilerin sosyal medyada gelişmeleri kaçırma korkusu davranışının daha yüksek düzeyde olmasını; kızların mizaç gereği özellikle ergenlik döneminde beğenilme, popüler olma davranışının daha fazla olması; sosyal medyada takdir görme ya da takip edilme açısından kızların daha baskın olduğu şeklinde yorumlanabilir.

Araştırmanın diğer bulgusunda anksiyetenin sosyal ortamlarda gelişmeleri kaçırma korkusunu (fomo) yordadığı, depresyonun ise açıklamadığı ortaya çıkarılmıştır. Anksiyetenin fomo'yu yordaması Elhai, Yang, Fang, Bai ve Hall (2020)'ın çalışmasıyla örtüşürken, Dhir, Yossatorn, Kaur ve Chen (2018), Baker, Krieger ve LeRoy (2016) ve Oberst, Wegmann, 
Stodt, Brand ve Chamarro (2017)'nın çalışma sonuçlarıyla farklılaşmaktadir.

Özellikle ergenlerin sosyal medyayı kullanım amaçları düşünüldügünde başkaları tarafından paylaşımlarının beğenilmesi, onun arkadaşlarından ilgi görmesine, dikkat çekmesine, popüler olmasına, bir gruba girmesine yol açabilir. Diğer bir ifade ile sosyal medya kullanımı arkadaşlık ilişkilerine yön verebileceği ifade edilebilir. Dolayısıyla internet teknolojilerinin kullanımı sonucunda sanal ortamdaki gelişme kaçırma bir bakıma ergenin arkadaşları arasındaki statünü ve değerini kaybetme algısı oluşturabilir. Bu durumda onun özellikle sosyal ağları kullanamadığı zamanlarda kaygisinin artmasina neden olabilir.

Depresyonun fomo'yu yordaması Elhai ve diğerleri (2020)'nin çalışmasıyla benzerlik göstermemektedir. Yine bu çalışmadan elde edilen sonuç Karadağ ve Akçınar (2019), depresyonu sosyal ortamlarda gelişmeleri kaçırma korkusunun yordadığını bulması ile tutarlılık göstermemektedir.

Depresyon'un sosyal ortamlarda gelişmeleri kaçırma korkusunu yordamaması depresyonun belirgin özelliklerden olan üzüntü, mutsuzluk, bir iş yaparken zevk almama ve yalnız kalma isteği ile bağdaştırmak mümkündür. Diğer bir ifade ile depresyon belirtiler gösteren kişilerin sosyal ortamlarda vakit geçirme ve gelişmeleri kaçırma konusunda isteksiz davrandığ1 düşünülebilir. Bu kişiler daha çok içine kapanma davranışları gösterip, zihinsel enerji tükenmişliği ile birlikte sosyal medyada vakit geçirme gibi farklı bir aktivite yapmakta problem yaşayabilecekleri söylenebilir.

Araştırmada elde edilen bir diğer bulgu ise sosyal ortamlarda gelişmeleri kaçırma korkusu ile mutluluk arasında anlamlı bir ilişkinin çıkmamasıdır. Alan yazında bu bulguyu destekleyen bir çalışmaya rastlanmamıştır. Buna karşın fomo'nun mutlulukla negatif ilişkili olduğunun saptanması ile (Roberts ve David, 2019), fomonun bireylerin mutluluğunu olumsuz etkilediği belirtilmesi (Alt, 2015) bu çalışmanın sonucuyla farklılaşmaktadır.

$\mathrm{Bu}$ araştırmada mutluluk ile sosyal ortamlarda gelişmeleri kaçırma korkusu arasında bir ilişkinin çıkmaması kişinin kendini iyi hissetmesi ve hayattan zevk alması ile fomo arasında bir bağlantının olmaması şeklinde değerlendirilebilir. 
Bu araştırma Erzurum ilindeki 517 lise öğrencisi ile sınırlıdır. Bu çalışma sonucunda öneriler şu şekilde sıralanabilir:

1. Araştırma kesitsel bir yönteme dayandığı için bulguların zaman içinde geçerliğini test etmek için boylamsal çalışmalar yapılabilir.

2. Sosyal Ortamlarda Gelişmeleri Kaçırma Korkusunun kişilik özellikleri, psikolojik ihtiyaçlar, sosyal medyayı kullanım amaçları gibi kavramlarla ilişkisi araştırılarak çalışma genişletilebilir.

3. Gelecekteki araştırmalarda görüşme, gözlem gibi nitel teknikler kullanılarak veri toplama yöntemi çeşitlendirilebilir.

4. Sosyal Ortamlarda Gelişmeleri Kaçırma Korkusunu azaltmaya yönelik grup psikoeğitim programları geliştirilip, okullarda görev alan rehber öğretmenlerin kullanımına sunulabilir. 


\title{
EXTENDED ABSTRACT
}

\section{The Investigation of Predictors of Fear of Missing Out (Fomo) in Adolescents}

\author{
Aslı Kartol - Adem Peker \\ National Education Ministy, Atatürk University
}

In connection with technology, the digital world has become indispensable for people and pushes the limits of tolerance in their absence. Many problems or fears experienced in the global world have now been added to fears such as running out of phone charging, running out of internet packages, and forgetting your smartphone at home. This fear of losing has become an increasingly global phenomenon (Schreckinger, 2014). FOMO is defined as strongly a severe sense of deprivation that individuals face due to the awareness of avoiding positive and self-relevant experiences that occur in their absence (Hayran, Anik \& Gürhan-Canli, 2017). The addictive use of smartphone is associated with mental health problems, especially depression and anxiety symptoms (Elhai, Levine \& Salon, 2019). Excessive and uncontrolled use of phones is becoming addictive (Griffiths, 2008). The aim of this study is to investigate the relationship between depression, anxiety and happiness as predictors of fear of missing out in adolescents.

\section{Method}

The aim of this study was to investigate the predictive relationships between adolescents' fear of missing out in social settings and happiness, depression and anxiety levels. It is based on a relational research model to determine whether two or more variables affect each other (Creswell, 2011). The study group consisted of 517 students studying at 9th, 10th and 11th grades in Mehmet Akif Ersoy Anatolian High School, Necmettin Erbakan Science High School and Nurettin Topçu Social Sciences High School in Erzurum. In the analysis of the data, it was examined whether there was asignificant difference between the fear of missing out and social development in terms of gender and independent samples $t$ test. 
Pearson correlation analysiswas used to determine the relationships between adolescents' social development, fear of missing out, happiness, depression and anxiety levels. In addition, the redictive relationship between happiness, depression and anxiety on fear of missing out was tested by multiple linear regression analysis.

\section{Results}

When the first finding of the study was examined; There was a significant difference between adolescents' fear of missing out and gender in favor of female students. Another result of the study is that there is a moderate positive relationship between the fear of missing out and the level of depression and anxiety. It was found that there was no significant relationship between fear of missing out and happiness. As a result of multiple linear regression analysis, it was found that anxiety explained $22 \%$ of fear of missing out; however, depression did not predict fear of missing out.

\section{Conclucion}

When the studies are examined; Eser and Alkaya (2019) found that girls had more social media addiction. This result is consistent with the research findings. Tolerance et al. (2017) found in their study on university students that fomo did not differ in terms of gender. Gökler et al. (2016) showed that fomo did not change according to gender. Female students' developments in social media have a higher level of fear of missing out; girls' temperament needs to be more popular, especially during adolescence; it can be interpreted that girls are more dominant in terms of appreciation or follow-up on social media. Another finding of the study is that there is a significant relationship between the fear of missing out and the level of depression and anxiety. When the studies on this subject are examined; Elhai et al (2020) found that internet addiction and psychological symptoms were examined in terms of various variables in adolescents and found that internet addiction had significant positive relationships with many psychological symptoms including depression and anxiety. Karadağ and Akçınar (2019) examined the predictors of the fear of missing out and found that neurotic personality structure, internet addiction and 
impulsivitypredicted the fear of missing out. Fear of missing out of people with others in real life, at home or in another place to be left alone by following what they do on the internet to follow the loneliness of the person by a kind of social (real) than thought that the person's social (real) environments more than the fear of the person increases. depressive mood. This fear can easily accompany the anxiety, as the fear of missing out canlead to comparison with others, and from time to time to be upset because others cannot live their experiences. The fact that there is no relationship between happiness and the fear of missing out, contrary to the expected results, may lead the person to short-term happiness even if it includes showing himself differently in social environments for a while; however, it can be interpreted that there will be no lasting happiness since the foundation is not solid.

\section{Kaynakça / References}

Alt, D. (2015). College students' academic motivation, media engagement and fear of missing out. Computers in Human Behavior, 49, 111-119. http://dx.doi.org/10.1016/j.chb.2015.02.057.

Albrecht, A. T. ve Herrick, C. R. (2007). 100 questions and answers about bipolar (manic-depressive) disorder. Sudbury, Mass: Jones and Bartlett.

Andreassen, C. S., Billieux, J., Griffiths, M. D., Kuss, D. J., Demetrovics, Z., Mazzoni, E., ve Pallesen, S. (2016). The relationship between addictive use of social media and video games and symptoms of psychiatric disorders: A large-scale cross-sectional study. Psychology of Addictive Behaviors, 30(2), 252-262.

Avenevoli, S., Stolar, M., Li, J., Dierker, L., ve Ries, M. K. (2001). Comorbidity of depression in children and adolescents: models and evidence from a prospective high-risk family study. Biological Psychiatry, 49(12), 1071-1081. doi: 10.1016/S0006-3223(01)01142-8.

Ay, İ., Seçer, İ. ve Şimşek, M.K. (2017). Adapting depression and anxiety questionnaire for children into turkish: Reliability and validity studies. International Education Studies, 10(3), 185-193. doi: 10.5539/ies.v10n3p185.

Baker, Z. G., Krieger, H., ve LeRoy, A. S. (2016). Fear of missing out: Relationships with depression, mindfulness, and physical symptoms. Translational Issues in Psychological Science, 2(3), 275. doi: 10.1037/tps0000075. 
Büyüköztürk, Ş. (2017). Sosyal bilimler için veri analizi el kitabı (23. Bask1). Ankara: Pegem Akademi.

Creswell, J. W. (2011). Educational research: Planning, conducting, and evaluating quantitative and qualitative research (4. Bask1). Boston: Pearson Press.

Çokluk, Ö., Şekercioğlu, G. ve Büyüköztürk, Ş. (2014). Sosyal bilimler için çok değişkenli istatistik SPSS ve Lisrel uygulamaları. Ankara: Pegem Akademi.

Deci, E. L. ve Ryan, R. M. (2012). Motivation, personality, and development within embedded socialcontexts: an overview of self-determination theory. (R. M. Ryan Der.), Oxford handbook of human motivation içinde (s. 85107). Oxford: Oxford University Press.

Demirci, İ. ve Ekşi. H. (2018). Keep calm and be happy: A mixed method study from character strengths to well-being. Educational Sciences: Theory $\mathcal{E}$ Practice, 18(29), 303-354. doi: 10.12738/estp.2018.2.0799.

Dhir, A., Dhir, A., Kaur, P., Yossatorn, Y., Kaur, P., Chen, S., ve Chen, S. (2018). Online social media fatigue and psychological wellbeing:A study of compulsive use, fear of missing out, fatigue, anxiety and depression. International Journal of Information Management, 40,141-152. doi: 10.1016/i.ijinfomgt.2018.01.012.

Diener, E. (2000). Subjective well-being. The science of happiness and a proposal for a national index. The American Psychologist, 55(1), 34-43. doi: 10.1037/0003-066X.55.1.34.

Dost, M. T. (2016). Öznel iyi oluş ölçeği'nin geliştirilmesi: Geçerlik ve güvenirlik çalışması. Türk Psikolojik Danışma ve Rehberlik Dergisi, 3(23), 103-111.

Dunn, E. W., Aknin, L. B., ve Norton, M. I. (2008). Spending money on others promotes happiness. Science, 319, 1687-1688. doi: 10.1126/science.1150952.

Ebesutani, C., Reise, S., Chorpita, B., Ale, C., Regan, J., Young, J., ve Weisz, J. (2012). The revised child anxiety and depression scale-short version: Scale reduction via exploratory bifactor modeling of the broad anxiety factor. Psychological Assessment, 24(4), 833-845. doi:10.1037/a0027283.

Elhai, J. D., Levine, J. C., Dvorak, R. D., ve Hall, B. J. (2016). Fear of missing out, need for touch, anxiety and depression are related to problematic smartphone use. Computers in Human Behavior, 63, 509-516. doi: 10.1016/j.chb.2016.05.079. 
Elhai, J. D., Levine, J. C., ve Hall, B. J. (2019). The relationship between anxiety symptom severity and problematic smartphone use: A review of the literature and conceptual frameworks. Journal of Anxiety Disorders, 62,45-52. doi: 10.1016/j.janxdis.2018.11.005.

Elhai, J.D., Yang, H., Fang, J., Bai, X, ve Hall, B.J. (2020). Depression and anxiety symptoms are related to problematic smartphone use severity in Chinese young adults: Fear of missing out as a mediator. Addictive Behaviors, 101, 1-7.

Eşer, A. K. ve Alkaya, S. A. (2019). Hemşirelik öğrencilerinin sosyal medya bağımlılık durumu ve gelişmeleri kaçırma korkusunun incelenmesi. Sağlık Bilimleri Üniversitesi Hemșirelik Dergisi 1(1), 27-36.

Francis, G. (1993). Depression and anxiety. (H. S. Koplewicz ve E. Klass Der.), Depression in children and adolescents içinde (4., s. 109-120). London: Routledge.

Giner-Bartolomé, C., Fagundo, A. B., Sánchez, I., Jiménez-Murcia, S., Santamaría, J. J., Ladouceur, R., Menchón, J. M., ... , Fernández-Aranda, F. (2015). Can an intervention based on a serious videogame prior to cognitive behavioral therapy be helpful in bulimia nervosa? A clinical case study. Frontiers in Psychology, 6, 982. doi: 10.3389/fpsyg.2015.00982.

Gökler, M.E., Aydın, R., Ünal, E. ve Metintaş, S. (2016). Sosyal ortamlarda gelişmeleri kaçırma korkusu ölçeğinin Türkçe sürümünün geçerlilik ve güvenilirliğinin değerlendirilmesi. Anadolu Psikiyatri Dergisi, 17(1), 53-59. doi: 10.5455/apd.195843.

Griffiths, M. D. (2008). Internet and video-game addiction. (C. A. Essau Der.), Adolescent addiction: Epidemiology, assesment and treatment içinde (s. 231267). New York, NY: Elsevier.

Hayran, C., Anik, L. ve Gürhan-Canli, Z. (2016). Exploring the antecedents and consumer behavioral consequences of "feeling of missing out (FOMO)". (M. Stieler Der.), Creating marketing magic and innovative future marketing trends içinde (s. 661-662). Springer, Cham. https://doi.org/10.1007/978-3-319-45596-9 127.

Hoşgör, H., Koç Tütüncü, S., Gündüz Hoşgör, D. ve Tandoğan, Ö. (2017). Üniversite öğrencileri arasında sosyal medyadaki gelişmeleri kaçırma korkusu yaygınlığının farklı değişkenler açısından incelenmesi. International Journal of Academic Value Studies, 3(17), 213-223. 
Huberty, T. J. R. (2012). Anxiety and depression in children and adolescents: Assessment, intervention, and prevention. New York: Springer.

Karadağ, A., ve Akçınar, B. (2019). Üniversite öğrencilerinde sosyal medya bağımlılığı ve psikolojik semptomlar arasındaki ilişki. Bă̆ımlılık Dergisi, 20 (3), 154-166.

Kozan, H. İ. Ö., Kavaklı, M., Ak, M., ve Kesici, Ş. (2019). Akıllı telefon bağımlılığı, genel aidiyet ve mutluluk arasındaki ilişkilerin yapısal eşitlik modellemesi ile incelenmesi. Klinik Psikiyatri, 22, 436-444.

Kutlu, M., Demir, Y., Erol, Y. C., ve Turhan, M. (2016, Mayıs). İnternet bağıml1lığ1 ile mutluluk arasındaki ilişkinin incelenmesi. Çanakkale On Sekiz Mart Üniversitesi VII. Uluslararası Eğitim Araştırmaları Kongresi. 5-8 Mayıs 2016. 205. http://congress.eab.org.tr/2016/media/2016 ozet kitap.pdf adresinden edinilmiştir.

Miller, J. A. (2002). Çocuklarda depresyon (M. Işık, çev. ed.). İstanbul: Özgür Yayınları. (Çalışmanın orijinali 1998'de yayımlanmıştır.)

Milyavskaya, M., Saffran, M., Hope, N. ve Koestner, R. (2018). Fear of missing out: prevalence, dynamics, and consequences of experiencing FOMO. Motivation and Emotion, 42(5), 725-737.

Nielsen, T. W. (2014). Finding the keys to meaningful happines: beyond being happy or sad is to love. (A. Batthyany ve P. Russo-Netzer Der.), Meaning in positive and existential psychology içinde (s. 81-93). New York: Springer Science+Business Media.

Oberst, U., Wegmann, E., Stodt, B., Brand, M., ve Chamarro, A. (2017). Negative consequences from heavy social networking in adolescents: The mediating role of fear of missing out. Journal of Adolescence, 55, 51-60. doi: 10.1016/j.adolescence.2016.12.008.

Parker, G. ve Roy, K. (2001) Adolescent depression: A review. Australian and New Zealand Journal of Psychiatry, 35(5), 572-580. doi: 10.1080/0004867010060504.

Przybylski, A. K., Murayama, K., DeHaan, C. R. ve Gladwell, V. (2013). Motivational, emotional, and behavioral correlates of fear of missing out. Computers in Human Behavior, 29(4), 1841-1848. doi: 10.1016/j.chb.2013.02.014.

Roberts, J.A., David, M.E. (2019). The social media party: fear of missing out (fomo), social media intensity, connection, and well-being. International Journal of Human-Computer Interaction, 1646517. 
Schmidt C., Muench R., Schneider F., Breitenbach S. ve Carolus A. (2018) Generation "always on" turned off. effects of smartphone separation on anxiety mediated by the fear of missing out. C. Stephanidis (Der.), Communications in computer and information science, vol 851. içinde (ss. 436443). Springer, Cham. doi: 10.1007/978-3-319-92279-9_58.

Schreckinger, B. (2014, July 29). The home of FOMO. Boston Magazine. 15 Haziran 2019 tarihinde http://www.bostonmagazine.com adresinden erişilmiştir.

Taylor, D. G. (2019) Social media usage, FOMO, and conspicuous consumption: an exploratory study. (P. Rossi ve N. KreyDer.), Finding new ways to engage and satisfy global customers içinde (s. 857-858). Springer, Cham.

Türkiye İstatistik Kurumu (2013). 06-15 yaş grubu çocuklarda bilişim teknolojileri kullanım ve medya. (Yayın No: 15866). 2 Ağustos 2019 tarihinde http://www.tuik.gov.tr adresinden erişilmiştir.

Wortham, J. (2011, April 9). Feel like a wallflower? Maybe it's your Facebook Wall. The New York Times. Accessed on 22th of June 2019 from http://wwwnytimes.com

\section{Kaynakça Bilgisi / Citation Information}

Kartol, A. ve Peker, A. (2020). Ergenlerde sosyal ortamlarda gelişmeleri kaçırma korkusu (fomo) yordayıcılarının incelenmesi. OPUSUluslararası Toplum Araştırmaları Dergisi, 15(21), 454-474. DOI: 10.26466/opus.628081 